\title{
On inferring selective association: Methodological considerations
}

\author{
DANIEL LINWICK, JEFF PATTERSON, and J. BRUCE OVERMIER \\ University of Minnesota, Minneapolis, Minnesota 55455
}

\begin{abstract}
The theoretically appropriate means for demonstrating selective association are discussed and shown to be empirically necessary. Following the acquisition of an unsignaled instrumental avoidance baseline, dogs received either CS-contingent shocks (CS+) or random, independent CS/shock presentations. The CS was either a tone or a flashing light. When the CSs were subsequently presented during avoidance responding, only the tone-CS+ group showed absolute facilitation of response rate. However, both tone- and light-CS+ groups showed facilitation relative to their respective random controls due to the nonassociative inhibitory effects of the light. A bidirectionally sensitive dependent variable enabled the detection of this pattern of effects. Thus, a demonstration of selective association requires (1) appropriate controls for nonassociative effects and (2) selection of a dependent measure that is sensitive to both excitatory and inhibitory influences.
\end{abstract}

Are all stimuli equally associable with a given reinforcer or are certain associations evolutionarily prepared and thus more readily established? The question has been addressed in such diverse domains as taste aversion (e.g., Garcia \& Koelling, 1966), operant learning (e.g., Foree \& LoLordo, 1973), and clincal psychology (e.g., Öhman, Fredrikson, Hugdahl, \& Rimmo, 1976). Although the concept of selective association has considerable theoretical import-note, for example, Seligman's (1970) "preparedness" concept-the experimental designs employed by those advancing the concept of selective association may not always warrant such conclusions (e.g., Mitchell, Scott, \& Mitchell, 1977; Riley, 1978; Schwartz, 1974). The purpose of the present experiment is to illustrate design and measurement considerations relevant to the assessment of selective association.

While it is tempting to argue for the differential associability of CSs with a given reinforcer on the basis of terminal performance, selective association implies more than simple differences in asymptotic levels of responding. Specifically, we take the term to imply that the rates at which stimulus-reinforcer associations are learned differ. Demonstration of such differential conditioning rates requires a reference point indicating where conditioning "begins," that is, an index of nonassociative effects (LoLordo, 1979).

Research was supported in part by Grant BNS-77-28161 from NSF to J. Bruce Overmier and by Grants BNS-77-22075 from NSF and HD-01136 and HD-00098 from NICHD to the Center for Research in Human Learning. Requests for reprints should be sent to J. Bruce Overmier, University of Minnesota, Department of Psychology, Elliott Hall, 75 E. River Road, Minneapolis, Minnesota 55455.
This reference condition must be sensitive to both excitatory and inhibitory effects of the CS (cf. Henderson, 1973). Some studies addressing the issue of selective association have failed to ascertain such a reference point, an oversight that reduces the force of their conclusions because stimuli may well differ with respect to nonassociative effects arising in the conditioning context.

Testa (1975), for example, offered evidence for selective association. Rats receiving conditioning trials in which the CS and US were similar in terms of spatial origin (floor or ceiling) and/or had similar temporal patterns (e.g., pulsed or constant) showed greater suppression of an operant baseline than did animals exposed to CSs and USs that were dissimilar on these dimensions. However, because there were no control groups equated on all factors save the CS-US contingency, there is no assurance that the differences in suppression were associatively based. Rather, it seems plausible that animals may become differentially sensitized or pseudoconditioned to stimuli having properties related to the US (see Wickens \& Wickens, 1942). Although Testa (1975, p. 121) noted the absence of control groups, those citing his data have not always appreciated its importance (e.g., Goudie \& Dickens, 1978). Thus, the Testa data are consistent with the notion of selective association but do not demonstrate it.

The same methodological complication arises in operant studies addressing the issue of selective association. Foree and LoLordo (1973), for example, employed a compound cue design to assess the relative ease with which a pigeon associated different stimuli (auditory and visual) and reinforcers (food and shock). One group of birds received shock avoidance training 
with a tone-plus-light compound, while another group pressed a treadle for food in the presence of the compound. Subsequent to this training, the degree of control exerted by each of the compound's elements was assessed, and a striking stimulus $x$ reinforcer interaction was observed. Avoidance was controlled primarily by the tone, while appetitive responding was controlled mainly by the light. This interaction, however, is not sufficient for inferring selective association. Shock may, for example, differentially and nonassociatively potentiate responses to light (e.g., freezing) that are incompatible with treadlepressing.

The two preceding examples illustrate, in principle, a need for explicitly assessing the degree to which any responding may reflect only nonassociative processes. An appropriate control for assessing nonassociative changes in responding to the CS should hold constant all the relationships and events except those that are necessary and sufficient for associative conditioning. Thus, control animals should experience the same number and distribution of CSs and USs as do experimental animals to provide a valid assessment of nonassociative phenomena such as sensitization to the CS, habituation to the US, pseudoconditioning, and unconditioned responding elicited by presentation of the CS. Rescorla (1967), on the basis of a contingency theory of classical conditioning, has argued for the use of the "truly random control" (TRC) for nonassociative effects. ${ }^{1}$ Independent of one's theory, the TRC procedure has the advantage of equating experimental and control groups on all factors except the CS-US dependency (see Rescorla, 1972). It does so by providing for random, independent presentation of CSs and USs to control subjects. Any nonassociative effects on the CS-either excitatory or inhibitory-resulting from CS and US presentations per se are reflected in the performance of these control subjects. The experimenter may thus obtain an unconfounded measure of the effects of any particular CS-US relationship by making appropriate group comparisons. Such a control can be easily incorporated into studies investigating the possibility of prepared CS-US associations.

Importantly, however, even the incorporation of nonassociative controls into the design is not sufficient to demonstrate selective association unless the response measure is sensitive to both excitatory and inhibitory nonassociative effects. To the extent that the selected dependent variable (e.g., latency, total number of responses, or rate of acquisition) is subject to floor (or ceiling) effects, this criterion of bidirectional sensitivity is not satisfied. And, indeed, it is common to use dependent measures that are so bounded in this kind of experimentation (e.g., Shettleworth, 1972; Wilcoxon, Dragoin, \& Kral, 1971). In such experiments, a group exposed to CS-US pairings could appear not to differ from its non- associative control because the performance of one of them is bounded by a floor (or ceiling); in this case, any inference of "no association" between the $\mathrm{CS}$ and the US would be spurious.

One solution to the problem of performance floors is the use of designs that infer conditioning from the capacity of a CS to modulate response baselines (i.e., the "transfer of control" paradigm; Trapold \& Overmier, 1972). There are now many demonstrations that this procedure, in which stimuli are superimposed upon ongoing baselines, is a methodology useful for detecting both excitatory and inhibitory stimulus effects (Bull \& Overmier, 1968; Rescorla \& LoLordo, 1965; Rescorla \& Solomon, 1967). In the present study, we utilized this technique in conjunction with truly random control groups to analyze an apparent instance of selective association.

\section{METHOD}

\section{Subjects}

Twenty-four mongrel dogs served as subjects. They were housed individually in a kennel with free access to food and water. One subject was dropped from the experiment due to a procedural error.

\begin{abstract}
Apparatus
The instrumental and the classical treatments were administered in two distinctively different apparatus units. The units were similar to those employed by Dorworth and Overmier (1977). The unit used during instrumental avoidance training (Phase 1) and final testing of the CSs (Phase 3) was a two-compartment, two-way shuttlebox. The two compartments were separated in the middle by an adjustable hurdle. The inside dimensions of each compartment were $122 \times 68 \times 99 \mathrm{~cm}$ (length $\times$ width $\times$ height). The floor of both compartments consisted of aluminum bars $3.5 \mathrm{~cm}$ wide and spaced approximately $1.5 \mathrm{~cm}$ apart. The inside walls were covered with aluminum sheeting painted flat black. Twentynine centimeters above the wire mesh ceiling of each compartment were mounted a $75-\mathrm{W}$ lamp ( $80 \mathrm{~cm}$ from the hurdle), a $15-\mathrm{W}$ lamp ( $7 \mathrm{~cm}$ from the hurdle), and a speaker $(61 \mathrm{~cm}$ from the hurdle). Throughout all experimental sessions, the 15 -W lamps were lit. Speakers presented white noise that, when combined with the sound of the exhaust fans, provided a background noise level of $70 \mathrm{~dB}$ (re $20 \mu \mathrm{N} / \mathrm{m}^{2}$ ). Presentation of a $200-\mathrm{Hz}$ tone CS increased the sound level to $73 \mathrm{~dB}$. Flashing of the $75-\mathrm{W}$ lamps at a rate of $10 \mathrm{~Hz}$ constituted the other CS. The CSs presented in the shuttlebox were identical to those employed in the classical conditioning apparatus (see below). The shock to be avoided was a .5-sec 8-mA shock delivered through the aluminum grid to the feet of the dog. To prevent the dog from maintaining a constant relationship to polarity by standing on particular bars (and thereby avoiding footshock), the polarity pattern was shifted among the grid bars 13 times/sec. Only the compartment occupied by the dog was electrified.

The classical conditioning phase (Phase 2) used a hammock supported by a wood frame, housed in a large, nonilluminated sound-attenuating cubicle. The hammock had holes in it through which the dog's legs extended and were secured. When dogs were in this apparatus, $5.0 \times 7.5 \mathrm{~cm}$ stainless steel plate electrodes were attached to the hind feet for delivery of shock (the US). The USs administered in Phase 2 were $1.0-\mathrm{sec}$ shocks of 10.0 -mA direct current. White noise at $65 \mathrm{~dB}\left(\right.$ re $20 \mu \mathrm{N} / \mathrm{m}^{2}$ ) masked extraneous noise. A $200-\mathrm{Hz}$ tone of $10-\mathrm{sec}$ duration (total ambient sound $=68 \mathrm{~dB})$ served as one CS, and a 10 -sec flashing light $(10-\mathrm{Hz}$, $75-\mathrm{W})$ served as another.
\end{abstract}




\section{Procedure}

Phase 1 was training in temporally paced unsignaled avoidance (Sidman avoidance). Subjects received three 50-min sessions of avoidance training. Failure to respond (to jump over the hurdle between compartments) resulted in the presentation of electric shocks at 5 -sec intervals ( $\mathrm{S}-\mathrm{S}=5 \mathrm{sec}$ ), while jumping the barrier postponed shock for $30 \mathrm{sec}(\mathrm{R}-\mathrm{S}=30 \mathrm{sec})$. Criterion performance was defined as five consecutive minutes of shock-free responding. All dogs attained the unsignaled avoidance criterion within the three sessions allotted.

Phase 2, classical conditioning, began the next day. Subjects were assigned randomly to one of the four conditions making up the $2 \times 2$ factorial design. One factor was contingency, and the other was CS modality. Subjects in all conditions were restrained in a hammock in the sound-attenuating cubicle, and electrodes were attached to their rear paws. The chamber was not illuminated during conditioning. The two CS-US contingency groups received 20 CS-US pairings (US onset contiguous with CS termination). These trials were presented on a variable-time $60-\mathrm{sec}$ schedule. For the two noncontingent groups, the $20 \mathrm{CSs}$ and $20 \mathrm{USs}$ were programmed independently, with each presented on a variable time $60-\mathrm{sec}$ schedule. Thus, in the second phase of the experiment, half of the subjects received contingent CS-US presentation, while the remaining subjects received independent presentations of the two events. Additionally, for half of the subjects in each of these groups the CS was the tone, while for the remaining subjects the CS was the flashing light.

Phase 3 was testing for the degree of control over avoidance responding exercised by the CSs. Subjects were returned to the shuttlebox at least $24 \mathrm{~h}$ following classical conditioning. Each subject's respective CS was superimposed 16 times on free operant avoidance responding during each of two 50 -min sessions. The rates of responding $10 \mathrm{sec}$ prior to and during $\mathrm{CS}$ presentation were recorded.

\section{RESULTS}

Each subject's rates of avoidance responding prior to (pre) and during CS were summed over trials, and the percent change in baseline during CS presentation was computed [100 (during-CS rate minus pre-CS)/ pre-CS rate]. The mean percent change for all four groups is presented in Figure 1.

The tone paired with shock (tone $\mathrm{CS}+$ ) facilitated responding relative to baseline $[\mathrm{t}(19)=2.64, \mathrm{p}<.05]$, while the light paired with shock did not $[\mathrm{t}(19)=.51]$. This is a pattern of differential behavior change that might lead one to infer selective association.

However, an analysis of variance of the percent changes from baseline for all four groups revealed that both the tone and the light CS + groups differed significantly from their corresponding TRC conditions [contingency $F(1,19)=5.71, p<.05$; stimulus $x$ contingency interaction $F(1,19)<1]$. Thus, although the light $\mathrm{CS}+$ failed to produce absolute facilitation, both the tone and light CS+ groups showed facilitation relative to their appropriate TRC controls.

\section{DISCUSSION}

The sensitivity of avoidance responding to a conditioned fear elicitor is well established. In the pres-

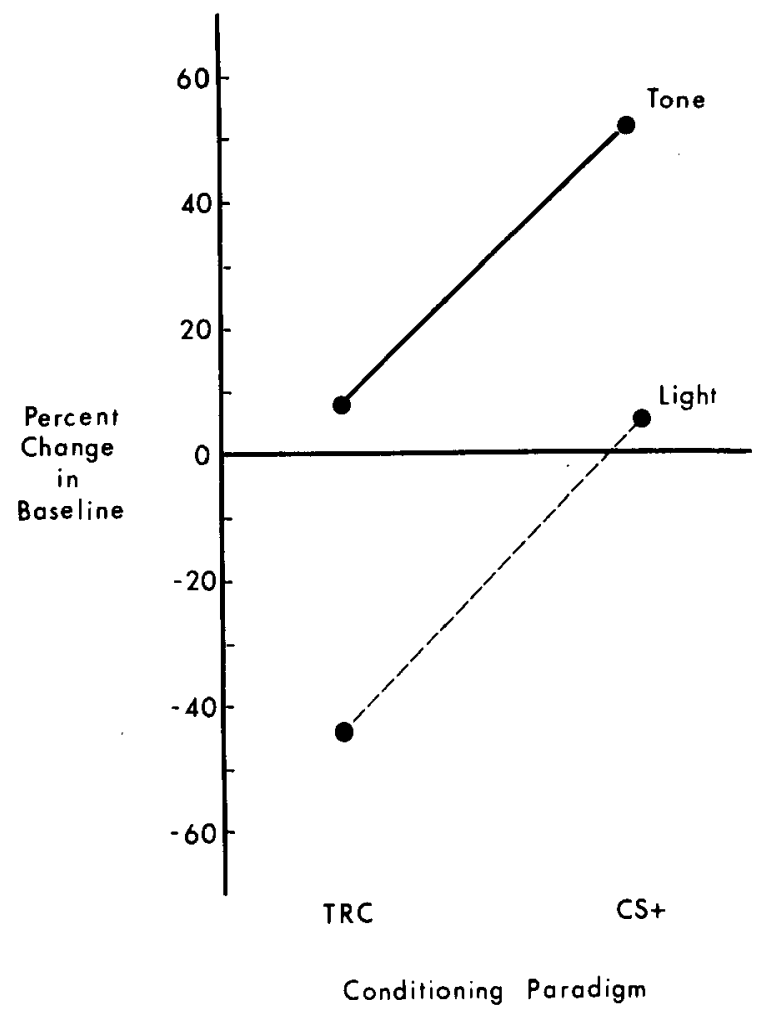

Figure 1. Mean percent change in baseline during CS presentation. Each point represents 32 observations for each of six dogs (five dogs for tone-CS+ group).

ent study, however, only the tone CS + produced the absolute facilitation typically taken as indicative of associative conditioning of fear. This might have been construed as reflecting selective association (i.e., "prepared" tone-shock or "contraprepared" light-shock association) had the truly random controls not been incorporated into our design. Reference to these controls, however, mitigates an interpretation in terms of "preparedness" because the nonassociative effects of the light and of the tone CSs differ. Inasmuch as the effects of the two CS+s relative to their respective TRC controls were virtually the same, dogs seem equally prepared to associate tone and flashing light with shock. The stimuli appear to differ only in their nonassociative effects.

Of course, the difference in nonassociative effects of these stimuli is itself important. Selective nonassociative effects, as demonstrated in our experiment, also require explanation (see LoLordo, 1979). However, we do wish to emphasize the distinction between selective associative and selective nonassociative effects and to note the insensitivity of many designs to these distinct alternatives. The nature of the theory called for to account for a selective associative effect differs fundamentally from that required to explain a selective nonassociative effect. 
Our results illustrate the theoretical and empirical necessity of employing adequate controls for nonassociative effects. Our results also illustrate that the addition of nonassociative controls alone is not in itself sufficient. Of equal importance in this study was the use of a conditioning measure sensitive to both facilitative and suppressive effects. Had such a measure not been utilized, incorrect conclusions almost certainly would have resulted, despite the use of truly random nonassociative controls. If our measure had been subject to a performance floor, no difference between the light-TRC group and light CS + group would have been apparent, thus leading to the incorrect inference that no light-shock association had occurred. However, a difference would have been observed between the tone $\mathrm{CS}+$ group and tone-TRC group. Such a pattern would likely result in the erroneous conclusion that learning had occurred only in response to the tone $\mathrm{CS}+$ but not to the light CS+ (i.e., selective CS-US association).

The present study differs from many selective association designs (e.g., Foree \& LoLordo, 1973; Testa, 1975 ) in that it included only one US and thus constitutes only half of a CS $\times$ US factorial combination (see Schwartz, 1974). While the factorial CS $\times$ US design is perhaps more common, single US designs are being utilized (Jacobs \& LoLordo, 1980). The advantage of the "double dissociation" technique is that it precludes explanation of the selective association in terms of nonspecific stimulus salience. If CS1 shows better conditioning than CS2 with one reinforcer, but CS2 shows better conditioning with another reinforcer, there is clear evidence that the organism is sensitive to both CSs. Nonetheless, even with the double dissociation technique, evidence of differential conditioning with a single US is required to infer selective association. A "crossover" interaction does not guarantee selective association, because positive contingency groups might still evidence no difference in conditioning relative to zero-contingency controls under each US condition (i.e., the interaction might be nonassociative). Thus, use of the double dissociation procedure does not eliminate the necessity of a sound nonassociative control reference condition or the need for a bidirectionally sensitive response measure.

Although the cases we have discussed above have revolved around selective excitatory associations, the same issues are relevant to demonstrations of selective inhibitory conditioning. A difference in amounts of apparent conditioned inhibition to two different CSs is not interpretable in the absence of assessment of the nonassociative effects of those two stimuli. To date, little attention has been given to the phenomenon of selective inhibitory associations.

In conclusion, our data demonstrate that "preparedness" arguments require appropriate controls for nonassociative effects in combination with bidirectionally sensitive dependent variables. Had either of these features not been included in our design, we could have incorrectly inferred that dogs selectively associate tone with shock. Thus, the consequences of failing to incorporate both design features are clear: incorrect conclusions regarding selective association. These issues are relevant to any assessment of selective association, regardless of paradigm (e.g., classical or instrumental), reinforcer (e.g., appetitive or aversive), quality of the association (e.g., excitatory or inhibitory), or specific design (single cue, compound cue, or double dissociation).

\section{REFERENCES}

Bull, J. A., \& Overmier, J. B. Additive and subtractive properties of excitation and inhibition. Journal of Comparative and Physiological Psychology, 1968, 66, 511-514.

Donworth, T. R., \& Overmier, J. B. On "learned helplessness": The therapeutic effects of electroconvulsive shocks. Physiological Psychology, 1977, 5, 355-358.

Fores, D. D., \& LoLondo, V. M. Attention in the pigeon: The differential effects of food-getting vs. shock-avoidance procedures. Journal of Comparative and Physiological Psychology, 1973, 85, 551-558.

Garcia, J., \& Koelining, R. A. Relation of cue to consequence in avoidance learning. Psychonomic Science, 1966, 4, 123-124.

Gormezano, F., \& Kenoe, E. J. Classical conditioning: Some methodological-conceptual issues. In W. K Estes (Ed.), Handbook of learning and cognitive processes: Conditioning and behavior theory (Vol. 2). Hillsdale, N.J: Erlbaum, 1975.

Goudie, A. J., \& Dickens, D. W. Nitrous oxide-induced conditioned taste aversions in rats: The role of duration of drug exposure and its relation to the taste aversion/self-administration "paradox." Pharmacology, Biochemistry and Behavior, 1978, 9, 587-592.

Hendersen, R. W. Conditioned and unconditioned fear inhibition in rats. Journal of Comparative and Physiological Psychology, 1973,84, 554-561.

JACOBs, W. J., \& LoLondo, V. M. Constraints on Pavlovian aversive conditioning: Implications for avoidance learning in the rat. Learning and Motivation, 1980, 11, 427-455.

LoLordu, V. M. Selective associations. In A. Dickinson \& R. A. Boakes (Eds.), Mechanisms of learning and motivation. Hillsdale, N.J: Erlbaum, 1979.

Mitchell, D., Scott, D. W., \& Mitchell, L. K. Attenuated and enhanced neophobia in the taste-aversion "delay of reinforcement" effect. Animal Learning \& Behavior, 1977, 5, 99-102.

Öhman, A., Fredrikson, M., Hugdahl, K., \& Rimmo, P. The premise of equipotentiality in human classical conditioning: Conditioned electrodermal responses to potentially phobic stimuli. Journal of Experimental Psychology: General, 1976, 105, 313-337.

RESCORLA, R. A. Pavlovian conditioning and its proper control procedures. Psychological Review, 1967, 74, 71-80.

Rescorla, R. A. Information variables in Pavlovian conditioning. Psychology of Learning and Motivation, 1972, 6, 1-46.

Rescorla, R. A. Some implications of a cognitive perspective on Pavlovian conditioning. In S. H. Hulse, H. Fowler, \& W. K. Honig (Eds.), Cognitive processes in animal behavior. Hillsdale, N.J: Erlbaum, 1978.

Resconla, R. A., \& Holland, P. C. Some behavioral approaches to the study of learning. In M. R. Rosenzweig \& E. L. Bennett 
(Eds.), Neural mechanisms of learning and memory. Cambridge, Mass: M.I.T. Press, 1976.

Rescorla, R. A., \& LoLordo, V. M. Inhibition of avoidance behavior. Journal of Comparative and Physiological Psychology, $1965,59,406-412$.

Rescorla, R. A., \& Solomon, R. L. Two-process learning theory: Relationships between Pavlovian conditioning and instrumental learning. Psychological Review, 1967, 74, 151-182.

RILEY, A. L. In response to and in defense of Mitchell and Revusky: An analysis of nonassociative effects. Animal Learning \& Behavior, 1978, 6, 472-473.

Schwartz, B. On going back to nature: A review of Seligman and Hager's biological boundaries of learning. Journal of the Experimental Analysis of Behavior, 1974, 21, 183-198.

Seligman, M. E. P. On the generality of the laws of learning. Psychological Review, 1970, 77, 406-418.

She TTLEWORTH, S. J. Stimulus relevance in the control of drinking and conditioned fear responses in domestic chicks (Gallus gallus). Journal of Comparative and Physiological Psychology, $1972,80,175-198$

Testa, T. J. Effects of similarity of location and temporal intensity pattern of conditioned and unconditioned stimuli on the acquisition of conditioned suppression in rats. Journal of Experimental Psychology: Animal Behavior Processes, 1975, 1, 114-121.
Trapold, M. A., \& Overmier, J. B. The second learning process in instrumental learning. In A. H. Black \& W. F. Prokasy (Eds.), Classical conditioning II: Current research and theory. New York: Appleton-Century-Crofts, 1972.

Wickens, D. D., \& Wickens, C. D. Some factors related to pseudo-conditioning. Journal of Experimental Psychology, 1942, 31, 518-526.

Wilcoxon, H. C., Dragoin, W. G., \& Kral, P. A. Illnessinduced aversions in rat and quail: Relative salience of visual and gustatory cues. Science, 1971, 171, 826-828.

\section{NOTE}

1. Gormezano and Kehoe (1975), on the basis of a contiguity theory of classical conditioning, have argued for use of the "explicitly unpaired control" in which both CSs and USs are presented but separated by intervals beyond the outer boundary of the CS-US contiguity gradient. Rescorla (1978) and Rescorla and Holland (1976) discuss other useful control procedures.

(Manuscript received September 21, 1980; revision accepted for publication August 3, 1981.) 